\title{
Sobre as ocupaçóes de idosos em condição de hospitalização: qual a forma e o significado?
}

\author{
Camila Rebeca Vieira de Almeida ${ }^{a}$, Airle Miranda de Souza ${ }^{a}$, \\ Victor Augusto Cavaleiro Corrêa ${ }^{b}$ \\ aUniversidade Federal do Pará - UFPA, Belém, PA, Brasil.

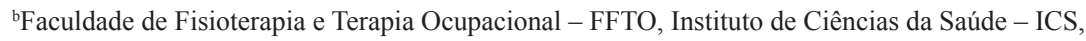 \\ Universidade Federal do Pará - UFPA, Belém, PA, Brasil.
}

\begin{abstract}
Resumo: Introdução: $\mathrm{O}$ envelhecimento é um fenômeno universal, complexo e multidimensional, que causa inúmeras repercussões nas ocupações e na participação social dos idosos. O processo de hospitalização, nesta fase da vida, pode repercutir nas ocupações rotineiras e significativas, gerando rupturas, mudanças e afastamentos das preferências ocupacionais do dia a dia. Objetivo: Considerando-se as possíveis repercussões do adoecimento e da hospitalização nas ocupações, na saúde e no bem-estar de pessoas idosas, esta pesquisa buscou compreender como se apresentavam a forma e o significado das ocupações de idosos em situação de hospitalização. Método: Trata-se de uma pesquisa de natureza qualitativa, do tipo exploratória descritiva. A pesquisa foi realizada na clínica médica de um hospital público no Estado do Pará, no período de maio a julho de 2013. Participaram da pesquisa 12 idosos, sendo aplicada uma entrevista semidirigida. As entrevistas foram analisadas através da análise do conteúdo. Resultados: A pesquisa revelou as experiências ocupacionais de idosos hospitalizados e que ocorreram mudanças no rol e nos ritmos das ocupações, e nas preferências ocupacionais. Verificou-se a ocorrência de perdas ocupacionais e alterações na forma e no significado das ocupações. Conclusão: A pesquisa ofereceu um espaço para que idosos pudessem expressar como percebiam suas ocupações durante a hospitalização. Tais relatos e registros podem auxiliar e contribuir na compreensão da dimensão ocupacional destas pessoas durante a hospitalização.
\end{abstract}

Palavras-chave: Envelhecimento, Unidades Hospitalares, Terapia Ocupacional.

\section{The elderly occupations in hospital of condition: what is the form and the meaning?}

\begin{abstract}
Introduction: Aging is a universal, complex, multidimensional phenomenon that causes numerous repercussions in the occupations and social participation of older people. The process of hospitalization at this stage of life can affect the routine and meaningful occupations, generating ruptures, changes and departures from occupational preferences of the daily routine. Objective: Considering the possible repercussions of illness and hospitalization in occupations, health and the elderly welfare, this research sought to understand the form and meaning of the nursing occupations in a hospital situation. Method: This is a qualitative, descriptive exploratory research. The survey was conducted in a public hospital clinic in the state of Pará, from May to July 2013. Twelve elderly participated of the research, using a semistructured interview. The interviews were analyzed by content analysis. Results: The survey revealed the occupational experiences of hospitalized elderly. The results showed changes in the occupational role, rhythms and preferences. We observed occupational losses and changes in the form and meaning of occupations. Conclusion: The research offered a space where older people could express how they perceived their occupations during hospitalization. Such accounts and records can help and contribute to the understanding of the occupational dimension of these people during hospitalization.
\end{abstract}

Keywords: Aging, Hospital Units, Occupational Therapy.

Autor para correspondência: Victor Augusto Cavaleiro Corrêa, Passagem Pinto Marques, 46, Bairro Marambaia, CEP 66615-880, Belém, PA, Brasil, e-mail: victorcavaleiro@gmail.com.

Recebido em Out. 3, 2015; $1^{\text {a }}$ Revisão em Fev. 18, 2016; $2^{\mathrm{a}}$ Revisão em Jul. 6, 2016; 3 ${ }^{\mathrm{a}}$ Revisão em Ago. 22, 2016 ; Aceito em: Set. 26 , 2016. 


\section{Introdução}

O envelhecimento populacional é um processo universal, que tem repercussóes para a pessoa idosa, a família, a comunidade e as políticas públicas (DALBOSCO, 2009). O Brasil, devido aos processos de transição demográfica, vem apresentando, de forma acelerada, um número crescente de idosos. No período de 2000 a 2050, está previsto que ocorra o maior crescimento na proporção desta parcela da população, de $5,1 \%$ para $14,2 \%$. De acordo com a Lei $n^{\circ} 10.741$, de $1^{\circ}$ de Outubro de 2003, a faixa etária dos idosos corresponde às pessoas com idade igual ou superior a 60 anos. Estima-se que, em 2025, 34 milhóes de brasileiros sejam idosos (MELO, 2007).

O processo de envelhecimento populacional também tem sido observado no Estado do Pará e na capital Belém. Dados do Instituto Brasileiro de Geografia e Estatística (IBGE) apontam que, em dez anos, o número de idosos no Estado quase dobrou. Em 2000, os paraenses maiores de 60 anos eram 356.562 , correspondendo a $5,75 \%$ da populaçáo estadual, que era de 6.192.307 habitantes. Em 2010, o número de idosos no Pará era de 603.379 habitantes e, atualmente, esta faixa etária já representa cerca de 8\% da população do Pará (7.443.904 habitantes). A capital Belém também acompanha o ritmo da transição demográfica e, em 2010, possuía uma população idosa total de 148.202 indivíduos, enquanto que, em 2000, eram apenas 88.860 (INSTITUTO..., 2010).

A pessoa idosa tende a utilizar mais serviços de saúde, sendo que as internações hospitalares são frequentes e o tempo de internação tende a ser maior, em relação a outras faixas etárias. As doenças com maior ocorrência em idosos são, predominantemente, crônicas, sendo comum a presença de comorbidades; assim, podem perdurar por vários anos, exigindo acompanhamento médico e de equipes multidisciplinares intensivas e especializadas. Em decorrência do adoecimento, o hospital pode ser um dos espaços onde ocorre a assistência à saúde de uma pessoa idosa (CAMARANO, 2002; VERAS, 2003; BRASIL, 2006).

A hospitalização pode ser considerada um evento estressor e potencialmente de risco para as pessoas idosas. As vivências relacionadas à doença; aos sintomas físicos; aos procedimentos, por vezes invasivos e dolorosos; às possíveis modificaçóes na capacidade funcional, e às mudanças de hábitos e rotina podem compor um quadro de vulnerabilidade. Dessa forma, o medo do desconhecido e a experiência da fragilidade, bem como o afastamento de pessoas, contextos e ocupaçôes significativos, podem ser condiçôes e sentimentos, frequentemente, experimentados durante a hospitalização (SIQUEIRA et al., 2004).

Por ser o ambiente no qual as ocupaçóes do idoso passam a ser desenvolvidas, o hospital pode tornar-se parte integrante da relaçáo de influência mútua e complexa entre os fatores pessoa, ambiente e ocupação. Nesse sentido, Rowles (2011, p. 82) cita o conceito de "contexto experimentado", que se refere à forma como a pessoa experimenta seu mundo e aos significados de viver em determinado lugar, atentando-se ainda para quais são as implicaçóes deste significado para a saúde e o bem-estar da pessoa.

Considerando-se o hospital como um espaço de atenção à saúde do idoso e a hospitalização como um evento potencialmente crítico, torna-se importante lançar um olhar para a pessoa idosa em situação de hospitalização, levando-se em conta as complexidades e as peculiaridades que podem estar envolvidas neste momento de vida caracterizado por "estar hospitalizado".

Uma das dimensões da vida que podem ser influenciadas pela hospitalização é a ocupacional. Dickie (2011, p. 16) afirma que a "ocupação é a própria vida”, o que evidencia que o homem é um ser ocupacional e que suas ocupações são um aspecto central de sua vivência.

As ocupaçóes relacionam-se não somente com a sobrevivência, mas também com a construção de papéis e identidades, bem como o estabelecimento da convivência social. Neste sentido, Larson, Wood e Clark (2005) afirmam que o envolvimento em ocupaçóes significativas relaciona-se com a composição da experiência do viver e pode apoiar a saúde e a satisfação com a vida e o bem-estar.

Ao estar hospitalizado, o idoso, em geral, é privado da realização de ocupaçóes que lhe sejam importantes, desejadas e significativas, pois, além de uma possível mudança na condição de saúde e na funcionalidade decorrente do adoecimento, há também o processo de hospitalização, em que a pessoa idosa é levada a permanecer em um ambiente diferente do habitual, passando a viver em um ritmo ditado pela rotina hospitalar e na companhia de pessoas que lhe são desconhecidas.

A Ciência Ocupacional, atualmente, tem se preocupado em compreender as experiências da pessoa em relação às suas ocupaçóes. Dessa forma, a Ciência da Ocupação é descrita como o estudo do homem como um ser ocupacional e visa identificar como os seres humanos entendem suas ocupaçóes 
(CLARK; WOOD; LARSON, 2002; CARRASCO; OLIVARES, 2008; PIERCE et al., 2010), ou seja, inclui a investigação sobre como e quais atividades são ou podem vir a ser significativas para os indivíduos dentro do contexto de suas vidas.

Consiste, entre os interesses da Ciência da Ocupaçáo, elucidar a forma, a função e o significado da ocupação, aspectos estes que resultam da interação dinâmica entre a pessoa, o ambiente e a atividade. A forma ocupacional é compreendida como o sistema objetivo de circunstâncias da ocupação, independente e externa à pessoa, referindo-se a "como" dada atividade é realizada; já a função relaciona-se ao propósito e à finalidade, ou "para quê" determinada pessoa envolve-se em uma atividade; e o significado refere-se aos aspectos simbólicos da ocupação, atribuídos pela pessoa e pela cultura, envolvendo o "por quê" realizar dado fazer (CARRASCO; OLIVARES, 2008).

Para Dickie (2011, p. 16), a compreensão da "experiência pessoal de realizar uma ocupaçáo" implica em desvendar, dentre outros aspectos: $\mathrm{O}$ que a pessoa faz? Como faz? Quando e onde acontece? Como esta ocupação se alterou com o passar do tempo? E o que significa este fazer?

Para Dickie (2011), as ocupações modificam-se ao longo do tempo e/ou de acordo com as condiçôes e o contexto em que a pessoa se encontra. Neste sentido, observou-se a importância de investigar e compreender as tessituras que compóem o engajamento ou não de idosos em ocupaçóes durante o período de hospitalização e quais os significados do envolvimento ou não envolvimento nestes fazeres.

A partir destas consideraçóes, esta pesquisa buscou compreender como se apresentavam as ocupaçóes de idosos em situação de hospitalização, com enfoque na forma e no significado pela qual estas ocupaçóes eram realizadas.

\section{Método}

\subsection{0 olhar}

Esta pesquisa foi ancorada na abordagem qualitativa. A investigação qualitativa propóe o estudo das pessoas e dos processos em seu ambiente natural, e busca compreender a perspectiva das pessoas, entender sua maneira de ver o mundo e sua construção subjetiva da realidade. Busca também descrever a maneira como os fenômenos ocorrem (TARRÈS; MONCLUS, 2009).

A abordagem qualitativa interessa-se pelas significações dos fenômenos em saúde, sendo apropriada para a investigação de um universo de significados, crenças, percepçôes, motivos, valores e atitudes, que correspondem a um espaço mais profundo das relaçóes, dos processos e fenômenos. Assim, a atenção é dada ao específico, ao peculiar, buscando a compreensão abrangente, por meio de várias perspectivas, e a descrição dos sentidos atribuídos pelos sujeitos (MARTINS; BICUDO, 1989; TURATO, 2003; MINAYO, 2008). Acredita-se que uma das formas de compreender a forma e o significado das ocupaçóes de idosos hospitalizados pode ser através das narrativas sobre suas experiências ocupacionais neste contexto e período de vida.

Chizotti (2003, p. 81) afirma que, na observação participante, os relatos de histórias de vida, relatos orais e entrevistas abertas reúnem um corpo qualitativo de informações:

Observando a vida cotidiana, ouvindo as narrativas, lembranças, biografias e valorizando o sentido dado pelo sujeito às suas açóes, obtém-se um volume qualitativo de dados originais e relevantes, não filtrados por conceitos operacionais, nem por índices quantitativos.

Esta abordagem é apropriada a uma pesquisa que visa promover a descrição das características da população-alvo, pela observação e interaçáo sistemática com o público pesquisado in loco.

\subsection{O lugar}

A pesquisa foi desenvolvida na Clínica Médica (CM) de um hospital da rede pública do Estado do Pará. As causas mais frequentes de internação na CM são: Diabetes Mellitus e suas complicações, Vasculopatias, Cardiopatias, Hepatopatias e Neoplasias, situaçóes que comumente apresentam período prolongado de internação, histórico de outras internaçóes e presença de comorbidades.

\subsection{As pessoas}

Participaram, desta pesquisa, 12 idosos, entre 60 e 77 anos de idade, em situação de hospitalização, no período entre maio e julho de 2013. Os participantes preencheram os critérios de inclusão, a saber: estarem internados na Clínica Médica de um hospital e aceitarem participar da pesquisa através da assinatura do Termo de Consentimento livre e Esclarecido (TCLE). Os idosos foram identificados com nomes próprios aleatórios, para que suas identidades fossem preservadas. 


\subsection{Procedimentos de coleta e análise dos dados}

Conforme a Resolução 466/12 do Conselho Nacional de Saúde (BRASIL, 2012), o projeto de pesquisa foi aprovado pelo Comitê de Ética em Pesquisa com seres humanos, com o parecer no 288.025 de 28 de maio de 2013.

A partir do aceite em participar da pesquisa, realizaram-se entrevistas semidirigidas, com cada idoso, contendo as seguintes perguntas disparadoras: "Como eram as suas ocupaçôes antes da hospitalização?"; "Quais os significados destas ocupaçóes?"; "Como se apresentam suas ocupaçóes no hospital?”; "Quais os significados destas ocupaçôes?"; e, por fim, "Como você se sentiu ao falar sobre suas ocupaçóes?".

Os relatos foram gravados em áudio, com o intuito de serem fontes de posterior análise. Para análise dos dados relacionados às narrativas, adotou-se como metodologia a análise do conteúdo, enfatizando os trechos dos relatos sobre as vivências ocupacionais colhidos nas entrevistas. Segundo Turato (2003, p. 313), a análise de conteúdo "[...] tem o formato apropriado para ser utilizado nas pesquisas qualitativas". A análise compreendeu a construção de unidades temáticas relacionadas às expressóes verbais recorrentes, que estáo intimamente vinculadas ao conceito de ocupaçáo.

\section{Como se Apresentam a Forma e o Significado Ocupacional de Idosos em Condição de Hospitalização}

Os relatos dos idosos sugerem que o agravamento dos sintomas era marcado por algumas mudanças nos fazeres e nas ocupaçóes tidas como importantes, significativas e rotineiras. Nesse sentido, esta pesquisa revelou que alteraçôes no aspecto ambiental - do ambiente domiciliar para o hospitalar - repercutiram nas ocupaçôes, na saúde, no bem-estar e na identidade ocupacional dos idosos.

Para os idosos participantes desta pesquisa, o adoecimento e suas implicaçóes, bem como a necessidade de hospitalização e o afastamento da rotina e das preferências ocupacionais, geraram modificações que impactaram na vida diária, alteraçôes que repercutiram na(s) forma(s) e no(s) significado(s) das ocupaçóes desses idosos, conforme os relatos a seguir:

Aqui mudou muito, né? Bem dizer, eu estou parada (Clarice).
Aqui a gente acorda, dorme um pouco; não dorme muito como é na nossa casa. Não é como a gente estar na casa da gente, né? Mas dá pra dar um sono aqui, a gente vai, levanta, dá uma sentada, e assim vai levando até o dia passar, a noite de novo. O que eu gosto mesmo eu não faço aqui; não tem como fazer o que a gente gosta aqui dentro do hospital. A gente tá num tratamento, $e$ a gente tem que seguir corretamente o tratamento médico (Mário).

$\mathrm{Na}$ perspectiva da Ciência Ocupacional, a ocupação é irrepetível. Por ser resultado de interaçôes dinâmicas e complexas, as mudanças em algum dos elementos que a compóem favorecem uma nova configuração no engajamento em ocupações. Nesse sentido, estar hospitalizado proporcionou uma experiência de pesar ${ }^{1}$ pelo afastamento e pela perda, ainda que temporários, da possibilidade de atravessar formas ocupacionais consideradas importantes e prazerosas, reforçando o imaginário de passividade, lugar de medicalização, cura e suspensão da vida de ocupaçôes diárias. Os fazeres diários foram alterados pela hospitalização, conforme relatos de Clarice e Bruno, respectivamente: "Me afastei de meus fazeres, sinto saudades de me embalar na rede e caminhar próximo minha casa" e "deitar na cama, com meu travesseiro".

De Carlo, Bartalotti e Palm (2004) afirmam que o hospital é uma instituição de grande complexidade administrativa. No hospital, são transmitidos saberes e discutidos temas significativos para os que são assistidos, como a fragilidade da vida, a iminência da morte, a dor, as rupturas do cotidiano, a preparação para o retorno à casa, entre outras situaçōes de vida.

Em linhas gerais, observa-se que a compreensão comum relacionada ao hospital refere-se a um lugar do "não fazer", acrescido do imaginário do paciente, especialmente o idoso, como um indivíduo passivo, que não precisa realizar nada além das suas atividades básicas. É como se, durante a hospitalização, a vida estivesse em uma espécie de suspensão, de espera, até o pleno reestabelecimento da saúde, muitas vezes identificada como restrita a aspectos físicos, como pode ser percebido no relato de Mário:

Aqui eu não tô feliz, de estar aqui, mas eu não estou pior por que estou correndo atrás da minha saúde. Se eu precisar ficar um, dois, três, quatro meses aqui, o importante é correr atrás da minha saúde.

Assim, a hospitalização é justificada como cuidado com a "saúde"; logo, é uma espécie de "mal necessário", que implica em afastamento e perda, ainda que temporários, de ocupaçôes significativas. 
Dessa forma, é necessário compreender que, além de aspectos clínicos e físicos, uma das repercussóes de um processo de adoecimento pode ser o afastamento de fazeres ou uma diminuição do engajamento pessoal em ocupaçôes diárias e significativas. Assim, os agravos à saúde podem ser experienciados também no âmbito ocupacional (HAMMELL, 2004).

Nesse sentido, observa-se que, na rotina hospitalar, a verificação de sinais vitais, a realização de exames, a preocupação com aspectos clínicos, a expectativa do paciente e da equipe pela "recuperação" da "saúde", as limitaçôes ambientais, entre outras condiçôes, podem ser fatores que repercutem nas ocupações durante a hospitalização, conforme os relatados abaixo:

Aqui melhora a minha saúde (chora), por que eu vim para cá muito doente, mas agora eu estou melhor. Aqui eu não posso estar andando, lá em casa eu andava; ia a pé para a casa dos meus filhos, ai eu botava o meu chapéu na cabeça, a minha sombrinha aqui por causa da chuva e ia me embora, ia andar (pausa). Aqui eu fico mais deitada (pausa). [...]. Eu gostava de andar. A cama daqui acaba a minha coluna. Em casa eu durmo a metade da noite na cama, e a metade na rede, por causa da minha coluna. Eu sinto falta da rede (Maria).

Aqui no hospital eu tô só me tratando, tomando remédio pra doença, e esperando a boa vontade de Deus pra me curar, e do doutor, pra me curar e voltar pra casa de novo (Bruno).

Observa-se que a centralidade em ocupações básicas, além da inserçâo em um ambiente diferente do habitual, marcado por uma rotina restrita, favorecem percepções de inadequaçáo ao lugar, estranhamento e dificuldades de adaptação, e reforçam a hospitalização como momento de suspensão, afastamento da vida cotidiana. Cecília comentou: "Ah, eu tomo porque eu tô aqui, né? É o jeito, mas eu tô me acostumando" (Sobre tomar café que não é feito por ela). Já Eneida relatou: "É da cama pra cadeira, e da cadeira para a cama. Sinto tristeza e desânimo". Ao comentar sobre o ambiente hospitalar, disse:

Aqui eu não me sinto bem, não. O banheiro é muito apertadinho, mas a gente ter que se acostumar com o bom e com o ruim. Na minha casa, o banheiro era dentro de casa, bem perto do meu quarto. $O$ ambiente é muito diferente. A minha casa tem dois quartos, banheiro, cozinha e sala. $E$ na frente de casa, tem a minifábrica, onde a gente costuma fazer polpa de fruta, de acerola, maracujá, сириaçu, muruci, tudo a gente faz. Aqui tem hora que eu fico assim, entristecida, mas Deus vai me fortalecendo. Não tem jeito, né? Eu fico assim. Nem todo dia a gente consegue estar forte, porque te aqueles dias da parte fraca, né? Ainda mais do jeito que eu estou (Emociona-se).

Mário também destacou a cama como uma síntese de suas ocupaçôes no ambiente hospitalar:

O meu dia a dia é aqui, né? Nesta parte aqui. Se fosse possivel, eu queria me livrar dela [da cama], $o$ mais rápido possivel.

Observa-se a expressão do pesar pelo "não fazer" no contexto hospitalar, quanto à escolha do ambiente que mais ocupa e/ou se ocupa neste espaço.

Sobre restriçôes ambientais, Hocking (2011) sinaliza que as barreiras físicas, sociais ou do ambiente podem exacerbar o impacto de um comprometimento ou de uma patologia, até o ponto em que a participaçáo na ocupação se torna insustentável.

Neste sentido, os pacientes podem experienciar uma rotina ocupacional marcada, em geral, pelos horários do banho, medicações, exames, refeições, sono, dentre outros. Na prática clínica, este sentimento pode ser traduzido por sentir-se "preso" no ambiente hospitalar.

Bruno revela: "quero voltar para casa e me ocupar dos meus afazeres" e Clarice diz: "só penso em quando eu voltar para meu lar [...], sinto saudades da minha vida". A hospitalizaçáo pode ser sentida como uma expectativa de retornar a fazeres e contextos significativos. Um olhar para fora, uma espera paciente, de um vir a fazer ou voltar a ser, como "tudo era antes".

Durante a hospitalização, todos os idosos têm direito a um acompanhante que possa fazer-lhe companhia e/ou auxiliá-lo, bem como a visitas diárias em dois turnos. Os participantes desta pesquisa relataram saudades devido ao afastamento dos entes queridos e das ocupaçôes que (com)partilhavam em contextos significativos de vida.

O que eu sinto mais saudade é de estar perto dos meus filhos; apesar deles não sairem daqui, mas é diferente de estar em casa, ainda mais o meu [filho] mais velho, é todo cheio de graça, chega aqui me beliscando, brincando comigo, e ninguém entende" - risos [...]. Eu estou com uma saudade grande, mas a gente vai superando, que são provaçôes da vida. Eu sinto falta do Centro (Espírita), mas sinto as vibraçôes que fazem para mim (Zélia).

Eu ficava me divertindo lá com os amigos, com as amigas. Na minha cidade eu tenho muitos amigos de pescaria. Os vizinhos se ajudam muito. Eu acho pescar muito bonito, e não é bom todo dia, mas quando Deus ajuda, a gente pesca que dá pra comer, 
ajudar os amigos [...]. Aqui eu sinto saudade de estar com meus companheiros, sinto saudade da mulher, mas é assim mesmo. Eu falo com ela todo dia pelo celular, todo dia a gente tem contato um com o outro, e eu fico mais conformado ouvindo a voz um do outro. Fica distante pra ela vim, $e$ ela é doente das pernas, ela tem cinquenta anos, já fica difícil para se deslocar pra cá (Bruno).

Alguns idosos relataram ainda um sentimento de pesar e sofrimento, presumindo que alguns fazeres significativos compartilhados com entes queridos haviam sido modificados ou estavam ausentes no momento da hospitalização:

Os meus vizinhos devem estar com saudades de mim, lá (Lygia).

Quando a gente viaja, eu ajudo todo mundo. Eu desço, subo do ônibus, ajudo as minhas companheiras. Tem uma que se eu náo viajar, ela não viaja. Agora, eu já falei que eu não vou, e ela já falou, que se eu não for, ela não vai (Clarice).

Diversamente, Eneida relatou sobre uma ocupação especial, a comemoração de seu aniversário, que envolvia a presença de "toda a família", seus entes queridos mais próximos; entretanto, estar com apenas uma das filhas, que assumia ali a condição de "acompanhante", foi percebido como uma ruptura dolorosa da ocupação na qual - e na forma como - costumavam se engajar nestas datas:

Eu sempre gostei de comemorar aniversário quando eu completava ano, ou do meu esposo, dos meus filhos. $O$ meu, eu passei aqui, eu chorei muito no dia, foi quarta-feira, mas fazer o quê? Tudo a gente passa na vida. Eu sempre passava aniversário com toda a minha família, mas agora, só essa filha que tava. Ela é minha acompanhante, fica sempre comigo (Eneida).

Uma peculiaridade das co-ocupaçóes é que muitas delas podem ser consideradas especiais pelo vínculo ou sentimento de intimidade ou identificação com aqueles com quem se compartilha dada ocupação. As pessoas com quem se atravessa dada forma ocupacional, ao comporem parte do ambiente, interferem diretamente no significado atribuído ao fazer.

Um dos relatos mais comoventes sobre co-ocupaçóes foi o de Raquel, que vivenciava a dolorosa perda recente de seu esposo, poucos dias antes de se internar no hospital. Ao contrário dos demais idosos participantes, sua narrativa era permeada de uma dor “sem expectativa” de melhora, ao voltar para casa.
Eu moro com os meus filhos, eu morava com o meu esposo, mas eu perdi ele há alguns dias (pausa). [...]. Ah, eu tô com muita dor, muita dor que ninguém tira (chora). Nós éramos casados há trinta e cinco anos. [...]. Eu sinto muita falta dele, e náo poder retribuir aquilo que ele fazia por mim, eu nunca pude fazer pra ele. [...] Eu tinha tanta vontade de sair, passear com ele, mas eu só vivia doente, e ele dizia: 'amor, não da pra gente sair assim, tu sente tontura, se sente mal'. [...] Ai nós 'saía' de bicicleta, ia na feira, comprar almoço (pausa). Era uma pessoa muito boa pra mim. Vai ser dificil me esquecer, muito dificil me esquecer. [...] A tristeza mesmo vai bater mais forte quando eu chegar em casa. Lá eu vou chegar, e não vou ver ele. Não vou mais poder fazer as coisas que eu fazia antes.

A morte de um ente querido é uma experiência que faz parte do ciclo de vida de todo ser humano. A reação subsequente a uma perda ou morte de um ente querido pode ser o luto. Assim, para haver luto, antes é necessário haver uma perda significativa (SOUZA; CORRÊA, 2009).

Nesse sentido, Raquel estava vivenciando um luto e grande parte de sua narrativa era tecida pela expressão de pesar pela perda de ocupaçóes que compartilhava com seu esposo. As formas ocupacionais que atravessavam juntos eram uma manifestação, uma concretização de uma relação e de um cuidado entre os dois.

Após este relato, Raquel chamou a atenção para uma árvore, a qual "eles nunca tinham visto". Não daquela forma, "amarela em flor". O olhar pela janela remetia ao tempo em que vinham juntos ao hospital. Sua expressão revelava pesar por aquilo que deixaram de viver e pelos fazeres que terá de vivenciar sozinha ou deixar de vivenciar pela perda de seu companheiro. Um pesar pela mudança na forma e no significado de muitas de suas ocupaçóes, especialmente no contexto domiciliar, que lhes era habitual. Esse quadro corrobora o estudo de Corrêa (2010), que verificaram que uma das formas de expressão do luto pode ocorrer nas atividades significativas do dia a dia.

Acredita-se que mudanças no engajamento em co-ocupacóes, sejam estas temporárias ou permanentes, estão presentes na ocasião da hospitalização. A escuta do possível pesar existente, subsequente a tais perdas, afastamentos e mudanças no âmbito ocupacional, precisa ser valorizada e estimulada neste contexto. Uma escuta atenta e sensível a estas demandas pode favorecer a expressão de tais sentimentos.

Compreende-se que as ocupaçóes podem ser compreendidas como um processo ativo de viver 
e apreciar a vida. Por ser complexa e sistêmica, a ocupação humana modifica-se devido à influência de inúmeros fatores que atravessam a existência humana, como as fases e os contextos de vida (DICKIE, 2011), o adoecimento, a hospitalização e as perdas.

A partir dos relatos dos participantes desta pesquisa, observou-se que o idoso, em sua inserção no hospital, pode assumir uma condição passiva e pouca (ou nada) participativa, do ponto de vista ocupacional. Em geral, a hospitalização é justificada como cuidado a "saúde"; assim, a ruptura e o afastamento das ocupaçóes, dos contextos e das pessoas significativas, ainda que temporariamente, passam a ser "toleráveis", aceitos e tidos como um fato não passível de reflexão e estratégias de mudanças.

Todavia, deve-se compreender que a saúde não se limita a aspectos físicos e orgânicos, e que a dimensão ocupacional é um aspecto central que pode influenciar diretamente na saúde e na vida destas pessoas, podendo influenciar o bem-estar, os níveis de satisfação e a qualidade do viver.

Quanto à relação ocupação e saúde, Hocking (2011, p. 50) afirma que, em geral, as pessoas vinculam sua saúde, dentre outros aspectos, ao fato de serem capazes de realizar suas ocupaçôes habituais, e que as pessoas se "transformam naquilo que elas fazem". Assim, o (não) engajamento em ocupaçôes pode influenciar na saúde, pois, por meio da ocupação, é possível a expressão de sentimentos, o desenvolvimento de habilidades, a experimentação de prazeres e o envolvimento nos contextos, que podem repercutir nas vivências e na percepção de bem-estar.

Compreendendo-se a centralidade da ocupação na vida das pessoas, torna-se importante conhecer como ocorre a experiência do envolvimento ou não envolvimento dos idosos em ocupaçôes significativas, em um contexto tradicionalmente tido como estressante, angustiante e traumatizante, como o hospitalar. Quais as repercussões destes fazeres ou não fazeres no enfrentamento do processo de adoecimento? Quais as possíveis repercussóes e mudanças relacionadas ao envolvimento ou não envolvimento em ocupaçóes significativas, e como estas apoiam ou não apoiam a saúde e o bem-estar dos idosos?

Construir significados a partir dos acontecimentos é a atividade básica de todo ser humano. E todas as demais atividades vitais, como pensar, sentir, fazer, dentre outras, ocorrem com respeito ao significado que a pessoa atribui à dada situação, a si mesma e ao contexto. A construção de significado através de uma experiência é um processo complexo e contínuo, e relaciona-se com um sentimento de identidade pessoal (HOCKING, 2011).

A dimensão ocupacional representa um aspecto central do viver humano; assim, as pessoas apresentam a necessidade de se envolverem em ocupaçóes que podem vir a ser plenas de valor e significado pessoal. As ocupaçóes modificam-se ao longo dos anos e de acordo com fatores da pessoa, da ocupaçáo em si e dos contextos (CLARK; WOOD; LARSON, 2002; DICKIE, 2011).

Dickie (2011) revela que as pessoas possuem uma necessidade biológica para se envolverem em ocupaçôes, a qual pode estar relacionada a aspectos ligados à sobrevivência (como, por exemplos, alimentar-se e realizar açóes de autocuidado), mas também ao processo prazeroso de viver e agir ativamente sobre o ambiente. Nesse sentido, a ocupação é compreendida como o processo ativo de viver, desde o início até o final da vida, envolvendo os processos ativos de cuidar de si e dos outros, apreciar a vida e ser produtivo, em diferentes contextos.

Compreende-se, assim, que as ocupações relacionam-se não somente com a sobrevivência, mas também com a construção de papéis, identidade e convivência social. Neste sentido, Larson, Wood e Clark (2005) afirmam que o envolvimento em ocupaçôes significativas relaciona-se com a composição da experiência do viver e pode apoiar a saúde, a satisfação com a vida e o bem-estar.

Cora refere: "aqui no hospital, gosto de ler e ver programas e revistas de culinárias", pois, em sua casa, gostava de cozinhar e ler revistas de receitas. Também observou-se, neste estudo, que idosos hospitalizados podem desenvolver estratégias cotidianas para adaptar ocupaçôes às demandas e restriçóes do contexto, de modo que possam continuar, em certa medida, engajando-se em fazeres significativos. Tais mudanças evidenciam-se, principalmente, na forma ocupacional e, consequentemente, influenciam os significados de realizar dadas ocupaçóes no hospital.

Ao agirem, no contexto, açóes cotidianas tornam-se uma experiência (cri)ativa durante a internação hospitalar e, por meio da percepção sobre a importância de algumas ocupaçóes em suas próprias vidas, alguns idosos conseguiram referir aprendizados e reflexôes, as quais podem ter repercussões para além da hospitalização, conforme relato de Antônio e Lygia, a seguir:

[...] vou procurar me ocupar de coisas mais saudáveis e, seguir minha dieta, quero respeitar mais as orientaçôes que meus familiares e amigos me dão [...], acho que devo escutá-los mais. 
Uma das mudanças na forma de se engajar em ocupaçóes decorreu do uso de tecnologias, como o uso de rádio, aparelhos celulares, aparelhos portáteis de televisão, por exemplo:

Eu gostava de ir para o campo [de futebol], mas agora não vou mais. Eu tenho o meu radinho bem aqui, mas tem um detalhe: eu ponho de um jeito que só eu mesmo escuto (aproxima a mão da orelha), bem baixinho (Antônio).

Neste caso, além de substituir a ida ao campo de futebol, por ouvir a narração dos jogos pelo rádio, Antônio preocupava-se em usar o recurso de acordo com limitaçôes ambientais, ouvindo de forma que somente ele escutasse. E, para ele, a modificaçáo na forma ocupacional auxiliou para o resgate de uma ocupação significativa, mesmo durante a hospitalização.

Clarice e Zélia também “precisaram” adaptar uma ocupação repleta de significados (assistir à programação de uma rede de televisão, por meio de um pequeno aparelho de TV móvel e celular), para continuar engajando-se neste fazer durante a internação:

Clarice nos revela:

Aqui eu gosto de assistir novela, futebol e jogo (risos). Olha, eu vejo futebol, basquete, vôlei. Se o Brasil jogar três, quatro horas da manhä, pode contar que eu vou estar assistindo. Eu assisto e nem cochilo.

Para esta idosa, a adaptação na ocupação atendia às suas demandas, mas sem uma preocupação com a rotina e as limitaçóes típicas do ambiente hospitalar.

Sobre as principais ocupaçóes no hospital, destacam-se os relatos de Clarice e Cora:

A gente sente muita saudade, e eu peço tanto a Deus para voltar, né? Para a minha rotina de sempre, né? Por que eu nunca fui de ficar parada, nunca fui de estar só dentro de casa dormindo, náo [...]. Um dia, en fui fazer a ultra [ultrassonografia], com isso [aponta para o equipamento], ai na hora que eu fui entrando, foi gol do Neymar (risos), ai ele [o funcionário] disse: "Não, não desligue, pode entrar com isso (risos)". Ai eu entrei, e fiz o exame com a televisão. Agora será que vão querer marcar amanhã de novo? Espero que não. A minha filha que fica dizendo: 'Mamãe, mas tem que fazer logo', mas eu digo: 'Não, na hora do jogo não, só quinta-feira (risos)!'.

Aqui no hospital, eu fico da cama, pra ali para a cadeira. Daqui pro banheiro; assisto uma televisãozinha aqui [no celular], vejo Ana Maria Braga, que eu gosto das receitas. Eu gosto do Edu
Guedes, o "Bem-estar", e eu gosto de assistir essas coisas.

Alguns idosos utilizam revistas, jornais e livros como uma forma de resgatar algumas ocupaçóes significativas. Neste sentido, observa-se a importância do engajamento em ocupaçóes com sentidos - um fator que apoia a satisfação, a saúde e o bem-estar.

Eu sou evangélica [...]. Aqui eu leio a biblia [...]. O que mais en gosto de fazer é cozinhar, eu passava o dia cozinhando, fazendo doces, salgados [...] aqui tem as minhas receitas, as minhas revistas dominicais; eu estava vendo até um bolo quatro-queijos, mas não posso me meter muito (risos). Esse telefone é o da minha filha, por que esse tem televisão. Eu me sinto muito com vontade de fazer, e não poder fazer. Eu sou muito ativa. Eu quero tanto voltar para o meu trabalho, mas meus filhos dizem que não. Por que alguns médicos já quiseram me dar um atestado para eu parar de trabalhar na copa, sabe, mas eu gosto muito (Cora).

É muito bonito, me 'entrete' muito. Aqui o que eu faço mais agora é estar lendo, trago os meus livros, que eu sou espirita. Ontem a enfermeira me trouxe três romances. Eu gosto muito de ler. Eu leio, guardo, empresto, e no fim do ano, a gente leva tudo embrulhado lá para o centro, por que tem gente que não pode comprar. Os livros são bem servidos. Eu estou com uma saudade grande, mas a gente vai superando, que são provaçōes da vida. Eu sinto falta do Centro, mas sinto as vibraçôes que fazem para mim (pausa); mas eu sei que tudo tem que acontecer como acontece. Se fosse para desencarnar agente ia embora, né? Eu estou preparada para tudo. A morte não é o fim de tudo. É a continuação da vida.

Cora revela a expectativa de poder retornar à forma ocupacional na qual costuma se engajar, em casa. Já em relação ao trabalho, o não fazer, associado às dúvidas sobre a possibilidade de retorno ao trabalho, gera um sofrimento relacionado ao âmbito ocupacional. Diversamente, Zélia relatou que uma das suas principais ocupaçóes no hospital era leitura de romances espíritas. No seu caso, a leitura havia sido disponibilizada por uma profissional do hospital e contribuía, inclusive, para a idosa expressar suas percepçóes e sentimentos a respeito da finitude da vida, tema este bastante recorrente no cotidiano hospitalar.

As narrativas de Cora e Zélia nos contam sobre diversas repercussóes do adoecimento e da hospitalização sobre as ocupaçôes. Percebeu-se a necessidade de favorecer a continuação do engajamento em fazeres 
que evoquem sentidos e significados, adaptando as ocupaçôes às restriçóes ambientais. Outro aspecto citado por alguns idosos foi a aprendizagem decorrente da vivência da hospitalização:

Eu confio em Deus, Ele vai me dar força, para eu normalizar os meus alimentos. Quero vim pra cá pra me cuidar, vim para as consultas, mas não aqui para o leito. Eu estava falando para os meus filhos, que a gente tem que se cuidar e fazer o máximo para não chegar aonde chega às vezes. E um aprendizado. Em casa, eu passava muito do limite, como the falei, eu trabalho com doces e salgados, e precisava ficar provando. Mas agora, eu vou fazer o possivel pra me cuidar (Cora).

Eu tô doido para sair daqui logo, para passear com a minha esposa. Aqui, a gente come o tempo todo na hora, tudo bonitinho, café, merenda, almoço, merenda e janta, e depois ainda tem um mingau. [...] Aqui veio uma amiga, que veio me falar sobre o Diabetes, e ela me explicou que toda vez que eu tomar banho, tenho que enxugar entre os dedos; ela me ensinou até onde eu vou comprar um sapato bom pra mim, é lá em M., que eu vou mandarfazer (pausa). A gente apanha, apanha, apanha, mas não pode pegar cacetada todo o tempo (Antônio).

Neste sentido, Antônio desejou registrar a entrada no Centro Cirúrgico, onde havia realizado cirurgia no membro inferior, devido a complicaçóes da Diabetes Mellitus, relatando:

Pra mim, esse hospital aqui é uma aula, uma aula mesmo, a gente vai aprendendo, por que o "caboco" só aprende quando apanha, né? [...].

Percebeu-se que uma das formas de refletir sobre esta aprendizagem ocorria através do engajamento em ocupaçóes comuns no ambiente hospitalar, como a forma de realizar as refeiçôes durante os procedimentos e atendimentos da equipe de saúde.

A partir destes relatos, compreendeu-se que era necessário que os membros da equipe considerassem os significados e as repercussôes ocupacionais que as vivências no hospital traziam para o idoso.

O significado implica uma interpretação pessoal, a qual também pode estar relacionada às circunstancias físicas, sociais e culturais, às crenças, às experiências, às habilidades, entre outras (LILLO, 2003), o que torna os significados das ocupaçôes únicos para cada pessoa. Assim, nota-se que as ocupaçóes sáo agentes poderosos que, além de dar significado à vida, permitem (re)significá-la.

Ainda que os idosos consigam continuar se engajando em ocupaçóes mais simples, como os autocuidados, a hospitalização gerou um importante afastamento de ocupaçóes relacionadas ao lazer, ao trabalho e às atividades instrumentais de vida diária, caracterizadas pela complexidade, como cuidar de outra pessoa e ser responsável pela administração doméstica e financeira; ou seja: ocorreram situaçôes que levaram os idosos a diminuir as possibilidades de decidir e realizar escolhas sobre seus fazeres e/ou envolver-se em ocupaçóes antes realizadas em contextos significativos de vida e/ou com pessoas queridas.

Nestas condiçôes, reside a importância de intervençóes que favoreçam o resgate dos sentidos e significados das ocupaçóes, estimulando o engajamento e criando estratégias de adaptação de formas ocupacionais, que atuem frente às limitaçóes do ambiente hospitalar. Faz-se importante que tais intervençóes busquem proporcionar experiências potencialmente significativas e favorecedoras de reflexão sobre os processos de saúde e de vida de cada idoso, mediante o atravessamento de novas formas ocupacionais.

Desta forma, destaca-se o terapeuta ocupacional como um profissional voltado para a escuta e o olhar para tais demandas, bem como um sensibilizador da equipe de saúde e articulador de estratégias que promovam o engajamento em ocupaçóes significativas para idosos durante a hospitalização. Acredita-se que esta pesquisa contribuiu para desvelar formas e significados das ocupaçóes de idosos em situação de hospitalização, além de possibilitar-lhes relatar os desejos, as perdas e as expectativas no campo do fazer. Mediante as mudanças na forma e no significado ocupacional, revelou-se um ser ocupacional que demanda cuidados e investigação.

Neste sentido, Hocking (2011) afirma que, embora a saúde facilite a participação, a participação na ocupação contribui para a boa saúde, que está vinculada ao que podemos chamar de "bem-estar" ocupacional.

\section{Conclusão}

Este estudo desvelou algumas vivências ocupacionais de idosos hospitalizados e ofereceu um espaço para que estas pessoas pudessem narrar, expressar e registrar suas percepçóes sobre suas ocupaçôes. Tais relatos e registros auxiliaram a apontar caminhos e contribuiçóes na compreensão da dimensão ocupacional destas pessoas, por ocasião da vivência da hospitalizaçáo. Ao ter, por fundamento, a centralidade da ocupação, a ênfase voltou-se para a pessoa que realiza o fazer 
e sobre como se apresentam as ocupaçóes de idosos internados.

O desvelamento da forma e os significados destes fazeres ou não fazeres para os idosos contribui para a reflexão sobre as repercussóes destas mudanças para a saúde e o bem-estar destes, bem como para o olhar dos terapeutas ocupacionais que atuam junto a idosos hospitalizados. Sugerem-se mais investigações sobre a dimensão ocupacional de pessoas que vivenciam ou vivenciaram um processo de hospitalização, principalmente pesquisas que possam conhecer o contexto em que essas pessoas realizam as ocupaçóes do dia a dia.

\section{Referências}

BRASIL. Ministério da Saúde. Secretaria de Atenção à Saúde. Departamento de Atenção Básica. Envelhecimento e saúde da pessoa idosa. Brasília: Ministério da Saúde, 2006.

BRASIL. Ministério da Saúde. Conselho Nacional de Saúde. Resoluçáo no 466/12, de 12 de dezembro de 2012. Diretrizes e normas regulamentadoras de pesquisa envolvendo seres humanos. Diário Oficial [da] República Federativa do Brasil, Brasília, DF, 12 dez 2012.

CAMARANO, A. A. Envelhecimento da populaçáo brasileira: uma contribuição demográfica. In: FREITAS, E.V.; PY, L. Tratado de geriatria e gerontologia. Rio de Janeiro: Guanabara Koogan, 2002. p. 58-71.

CARRASCO, M. J.; OLIVARES, A. D. Haciendo camino al andar: construcción y comprensión de la Ocupación para la investigación y práctica de la Terapia Ocupacional. Revista Chilena de Terapia Ocupacional, Santiago, n. 8, p. 5-16, 2008.

CHIZOTTI, A. Pesquisa em ciências sociais. São Paulo: Editora Cortez, 2003.

CLARK, F.; WOOD, W.; LARSON, E. Ciência ocupacional: legado da Terapia Ocupacional para o século XXI. In: NEISTADT, M. E.; CREPEAU, E. B. (Org.). Willard \& Spackman: Terapia Ocupacional. Rio de Janeiro: Guanabara Koogan, 2002. p. 10-17.

CORRÊA, V. A. C. Luto: intervenção em Terapia Ocupacional. Belém: Editora Amazônia, 2010.

DALBOSCO, S. N. P. O idoso hospitalizado: perspectivas do próprio sujeito a respeito de si mesmo, dos familiares e dos profissionais cuidadores. 2009. 143 f. Dissertação (Mestrado em Educação) - Universidade Federal do Rio Grande do Sul, Porto Alegre, 2009.

DE CARLO, M. M. R. P.; BARTALOTTI, C. C.; PALM, R. D. C. M. A Terapia Ocupacional em reabilitação física e contextos hospitalares: fundamentos para a prática. In: DE CARLO, M. M. R. P.; LUZO, M. C. M. Terapia Ocupacional: reabilitaçáo física e contextos hospitalares. São Paulo: Roca, 2004. p. 3-28.
DICKIE, V. O que é ocupação? In: CREPEAU, E.; COHN, E.; SCHELL, B. Willard \& Spackman: Terapia Ocupacional. Rio de Janeiro: Guanabara Koogan, 2011. p. 15-21.

FRANCO, M. H. P. Uma mudança no paradigma sobre o enfoque da morte e do luto na contemporaneidade. In: FRANCO, M. H. P. Estudos avançados sobre o luto. Campinas: Livro Pleno, 2002. p. 15-38.

HAMMELL, K. W. Dimensions of meaning in the occupations of daily life. Canadian Journal of Occupational Therapy, Toronto, v. 71, n. 5, p. 296-305, 2004.

HOCKING, C. Contribuição da ocupação para a saúde e o bem-estar. In: CREPEAU, E.; COHN, E.; SCHELL, B. Willard \& Spackman: Terapia Ocupacional. Rio de Janeiro: Guanabara Koogan, 2011. p. 45-55.

INSTITUTO BRASILEIRO DE GEOGRAFIA E ESTATÍSTICA - IBGE. Censo 2010. Rio de Janeiro, 2010. Disponível em: <http://censo2010.ibge.gov.br/>. Acesso em: 18 jan. 2013.

LARSON, E.; WOOD, W.; CLARCK, F. Ciencia Ocupacional: Desarrollo de la ocupacion a traves de uma disciplina academica. In: CREPEAU, E. B.; COHN, E. S; SCHELL, B. A. B. Willard \& Spackman: Terapia Ocupacional. Buenos Aires: Medica Panamericana, 2005. p. $16-26$.

LILLO, S. G. La ocupación y su significado como factor influyente de La identidad personal. Revista Chilena de Terapia Ocupacional, Santiago, n. 3, p. 43-47, 2003.

MARTINS, J.; BICUDO, M. A. V. A pesquisa qualitativa em Psicologia: fundamentos e recursos básicos. São Paulo: Moraes/Educ, 1989.

MELO, M. M. Prevenção de acidentes domésticos em idosos: relato de experiência. In: SIMPÓSIO DE ENSINO DE GRADUAÇÃO, 5., 2007, Piracicaba. Anais... Piracicaba: UNIMEP, 2007. p. 1-4. Disponível em: <http://www. unimep.br/phpg/mostraacademica/anais/5mostra/4/240. pdf>. Acesso em: 10 dez. 2010.

MINAYO, M. C. S. O desafio do conhecimento: pesquisa qualitativa em saúde. São Paulo: Editora Hucitec, 2008.

PIERCE, D. et al. Occupational science: a data-based American perspective. Journal of Occupational Science, Australia, v. 17, n. 4, p. 204-215, 2010.

ROWLES, G. D. O significado do lugar. In: CREPEAU, E.; COHN, E.; SCHELL, B. Willard \& Spackman: Terapia Ocupacional. Rio de Janeiro: Guanabara Koogan, 2011. p. 81-90.

SIQUEIRA, A. B. et al. Impacto funcional da internação hospitalar de pacientes idosos. Revista de Saúde Pública, São Paulo, v. 38, n. 5, p. 687-694, 2004.

SOUZA, A. M.; CORRÊA, V. A. C. Compreendendo o pesar do luto nas atividades ocupacionais. Revista do NUFEN, São Paulo, v. 1, n. 2, p. 131-148, 2009. 
TARRÈS, J. P.; MONCLUS, P. G. Etnografía(s) para la investigación en Terapia Ocupacional. In: PIMENTEL, A.; OLIVEIRA, I.; ARAÚJO, L. Pesquisas qualitativas em Terapia Ocupacional. Belém: Amazônia, 2009. p. 3966.

TURATO, E. R. Tratado da metodologia da pesquisa clínico-qualitativa: construção teórico-epistemológica, discussão comparada e aplicação nas áreas da saúde e humanas. Petrópolis: Vozes, 2003.

VERAS, R. Em busca de uma assistência adequada à saúde do idoso: revisão da literatura e aplicação de um instrumento de detecção precoce e de previsibilidade de agravos. Cadernos de Saúde Pública, Rio de Janeiro, v. 3, n. 19 , p. 705-715, 2003.

\section{Contribuição dos Autores}

Camila Rebeca Almeida: realizou a pesquisa de campo, análise e organização dos dados, e redação do artigo original. Airle Miranda de Souza: realizou a revisão do trabalho. Victor Augusto Cavaleiro Corrêa: orientador da pesquisa, realizou supervisão e revisão do trabalho e a elaboração do artigo. Todos os autores aprovaram a versão final do texto.

\section{Notas}

${ }^{1}$ Pesar: Neste estudo, compreende-se como o complexo de pensamentos e sentimentos sobre uma perda, que são vivenciados internamente, sendo o significado interno dado à experiência do luto, sendo este externalizado com aqueles que o cercam (FRANCO, 2002). Assim, o pesar é conhecido quando oferecemos uma escuta a quem vivência uma perda significativa e quando este se dispóe a compartilhar estes pensamentos e sentimentos. 